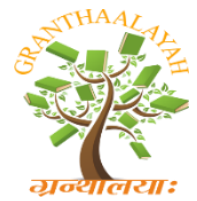

\author{
INTERNATIONAL JOURNAL OF RESEARCH - \\ GRANTHAALAYAH \\ A knowledge Repository
}

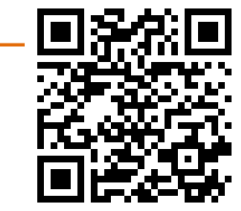

Science

\title{
USING ADOBE (CLAY SOIL) MIXED WITH QUARTZ (SHARP SAND) TO DETERMINE THE THERMAL COMFORT OF RESIDENTIAL BUILDING IN NORTH-MUBI L. G, ADAMAWA STATE, NIGERIA
}

\author{
S. K Singh ${ }^{1}$, H. P Wante ${ }^{2}$, S. M Ngaram ${ }^{3}$ \\ ${ }^{1}$ Department of Physics, Adamawa State University Mubi, Adamawa State, Nigeria \\ ${ }^{2}$ Department of Physics, Federal University Gashua, Yobe State, Nigeria \\ ${ }^{3}$ Department of Science Laboratory Technology (Physics Unit), Federal Polytechnic Mubi, \\ Adamawa State, Nigeria
}

\begin{abstract}
The adobe structure is constructed by using low energy materials like adobe soil and sand etc. Adobe and cob are terms often used to describe sun dried clay materials. Adobe is a Spanish word derived from the Arabic atob, which literally means sun dried bricks. This paper investigated the thermal conductivity of Adobe mixed with Quartz in view of their availability usage as building materials. The thermal conductivities of disc made from Adobe-Quartz chippings were determined, the values obtained were between $0.57 \mathrm{Wm}-1 \mathrm{k}-1$ and $0.91 \mathrm{Wm}-1 \mathrm{k}-1$, and these values could be used to identify Adobe-Quartz as one of the engineering materials used in building construction, adopted to reduce the temperature of buildings without the need for power consumption. Consequently, the aim of this study is to test the usefulness of applying selected Adobe-Quartz to improve thermal performance and to reduce energy consumption of residential buildings in hot arid climate setting, Mubi, Adamawa State, Nigeria. Energy reduction was achieved by making the Adobe-Quartz into bricks used as aggregates in walls. Adobe-Quartz was made in disc form of the same thickness and diameter, by proportions of Adobe to Quartz (90:10, $85: 15,80: 20)$, i.e. 10 samples for each ratio. The average values of the thermal conductivities were between $0.07 \mathrm{Wm}-1 \mathrm{k}-1$ and $0.93 \mathrm{Wm}-1 \mathrm{k}-1$, the least thermal conductivity value was $0.57 \mathrm{Wm}-1 \mathrm{k}-$ 1 for the ratio of $(90: 10)$. MATLAB 7.0 and EXCEL software were used in the various computations. An average correlation coefficient, R2 of 0.75 was existed between Adobe-Quartz ratios to thermal conductivities.
\end{abstract}

Keywords: Thermal Conductivity; Adobe; Quartz; Lee Discs.

Cite This Article: S. K Singh, H. P Wante, and S. M Ngaram. (2019). "USING ADOBE (CLAY SOIL) MIXED WITH QUARTZ (SHARP SAND) TO DETERMINE THE THERMAL COMFORT OF RESIDENTIAL BUILDING IN NORTH-MUBI L. G, ADAMAWA STATE, NIGERIA." International Journal of Research - Granthaalayah, 7(3), 274-281. https://doi.org/10.29121/granthaalayah.v7.i3.2019.973. 


\section{Introduction}

The adobe structure is constructed by using low energy materials like adobe soil and sand etc. Adobe and cob are terms often used to describe sun dried clay materials [1]. Adobe is a Spanish word derived from the Arabic a to b, which literally means sun dried bricks. Adobe is one of man's first building materials. [12] Has carried out detailed study on rural built environment. According to the United Nations an estimated $30 \%$ of the world population still lives in houses constructed using unbaked bricks. The mass of Adobe walls will absorb heat and radiates it back out into the house at night. In summer the converse is true. Thus, the swing in temperature inside the house is very mild. Adobe construction in combination with good passive solar design and techniques makes for an effective energy-saving solution in cold winter and hot summer areas. [2] Have carried out detailed study which has shown effect of various factors on thermal performance of Adobe construction. The effect of wall thickness, thermal conductivity, and heat capacity has been studied by [6]. In the last few decades the use of energy stored in the ground for heating/cooling of buildings and greenhouses has been received an increasing importance [5], [4], [11], [8], and [7]. At the same time, the energy losses in building will take place through building envelope. In order to reduce heat losses, either use of insulation material in building or use of thermal mass options for minimizing energy loss and keep the houses cool in summer and hot in winter. Building material such as dried mud-brick has been use for construction work in Mubi North. This study focused mainly on energy saving of an adobe mixed with quartz i.e. sun dried mud-brick structure by the application of thermal insulation. Material such as mud brick has been widely used rural areas of Adamawa. Mud brick is environmentally friendly. It possesses high thermal capacity and acts as heat sink in extreme weather conditions. Quartz (sand) can also be used as a building material. It is mixed with clay (adobe) to produce mud brick. It also possesses good insulation properties. The energy requirement in a building can be reduced to minimum by the application of thermal mass of mud wall. At optimum insulation thickness, the total cost is minimum and energy saving is maximum. It is, therefore, recommended to apply the optimum insulation thickness for building walls.

To fulfill the outline of the present paper, a literature review with scope of paper is given as follows.

[3] reported that the mud house construction have natural air conditioning effect because the rooms are cool during day time and warm during night time. The application of mud as wall material was investigated to control room air temperature for buildings by [9]. The most common passive solar building architecture comprises of massive walls to reduce the temperature fluctuations inside a building. This is known as the thermal flywheel effect as mentioned by [10]. The popular mudhouses in Yemen city utilize this effect. The use of mud as building material is of great concern not only for the people in hot developing countries, but also for those in cold industrialized countries in Europe and America. Hence the objective of this paper is to calculate the thermal conductivity of Adobe mixed with Quartz used to determine the thermal comfort of residential building.

\section{Mud's Specification}

Soil used for adobe brick should have a high enough clay content to make the brick humidity resistant and more strength. However, brick with too much clay in it will develop shrinkages upon drying. To overcome this, sand must be added. The recommended mixture of adobe bricks are 
$10 \%$ of sand mixed with $90 \%$ of clay, $15 \%$ of sand mixed with $85 \%$ of clay and $20 \%$ of sand mixed with $80 \%$ of clay. With these compositions, adobe bricks provide good structural behavior, but they need protection from continuous exposure to high moisture. In addition, adobe bricks possess very good sound insulation properties, and excellent thermal and fire resistance.

\section{Sample Preparation}

A $10 \%, 15 \%$ and $20 \%$ (by mass) of three portions of sand were mixed separately with adobe mud of $90 \%, 85 \%$ and $80 \%$ respectively. Each sample was formed by using a metal mold. The mold was constructed of $1.77 \mathrm{~cm}$ thick with dimension of $0.3 \times 0.3$ and $0.3 \times 0.5$ inches. A mixed mud was poured into the mold, hand tamped, and leveled. The samples then were pulled out from the mold and left several days until became dried.

Lee's disc apparatus was used to determine the thermal conductivity of the samples, and steady state method.

\section{Experimental Procedures}

The apparatus is shown in fig 1, below. A steam was passed through the upper slab B, from a steam boiler and the temperature recorded by two thermometers $T_{1}$ and $T_{2}$, when the steady state temperature has reached. Upper slab was now removed, the lower slab $\mathrm{C}$, is still suspended. Heat $\mathrm{C}$ directly by the steam chamber, until $\mathrm{T}_{2}$ recorded the temperature up to $10^{\circ} \mathrm{C}$ higher than that recorded in the steady state. Removed the steam chamber and wait for 2-3 minutes, so that heat is uniformly distributed over the disc and placed the insulating material on C. Start recording the temperature at interval of 30 second is taking, using stop watch, continue till the temperature falls by $10^{\circ} \mathrm{C}$ below steady state temperature from $\mathrm{T}_{1}$, which use the steady- state method technique.

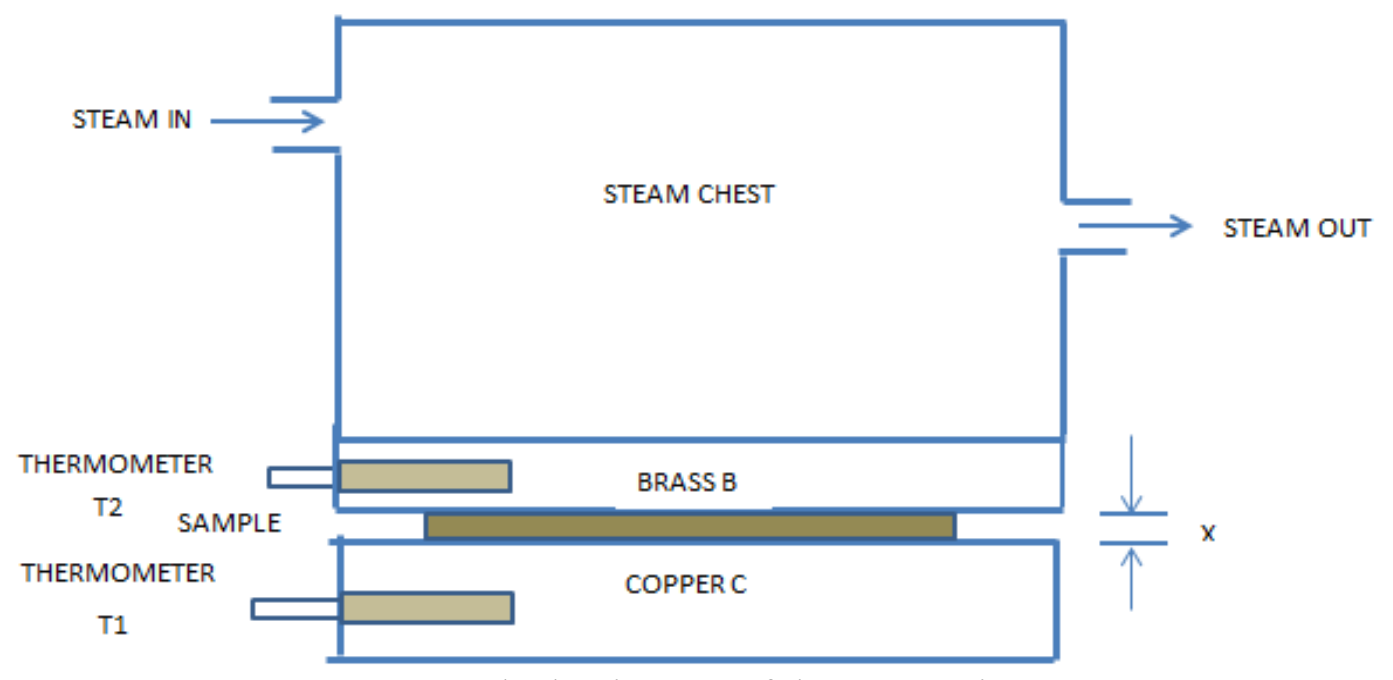

Figure 1: A Block Diagram of the Lee's Disc Setup

\section{Results and Discussion}

Experiments indicated that the mud samples with sand (90:10) have a low thermal conductivity, followed by the mud brick samples with sand (80:20) and mud brick samples with sand (85:15) have higher thermal conductivities. 
Table 1: Sample $1_{\mathrm{a}-\mathrm{j}}(80: 20)$, measured values

\begin{tabular}{|c|c|c|c|c|c|}
\hline \multirow{2}{*}{$\begin{array}{c}\text { Sample } \\
\text { Number }\end{array}$} & $\begin{array}{c}\text { Root mean } \\
\text { Square Error } \\
\text { (RMSE) }\end{array}$ & \multicolumn{2}{|c|}{$\begin{array}{c}\text { Disc } \\
\text { Temperature } \\
(\mathbf{O} \mathbf{C})\end{array}$} & \multirow{2}{*}{$\begin{array}{c}\text { Thermal } \\
\text { Conductivity K } \\
\left(\mathbf{W m}^{-\mathbf{1}} \mathbf{K}^{-\mathbf{1}}\right)\end{array}$} & $\begin{array}{c}\text { Correlation } \\
\text { Coefficient } \mathbf{R}^{\mathbf{2}}\end{array}$ \\
\cline { 3 - 4 } & & $\mathbf{T}_{\mathbf{2}}$ & $\mathbf{T}_{\mathbf{1}}$ & & \\
\hline 1a & 0.5200 & 97 & 46 & 0.3212 & 0.9713 \\
\hline 1b & 2.0370 & 97 & 58 & 0.5050 & 0.9420 \\
\hline 1c & 1.5470 & 97 & 59 & 0.6158 & 0.9618 \\
\hline 1d & 0.78 .92 & 96.7 & 60.1 & 0.6553 & 0.9861 \\
\hline 1e & 0.6599 & 96.5 & 60.4 & 0.6482 & 0.9914 \\
\hline 1f & 1.0900 & 96 & 63 & 0.7445 & 0.9700 \\
\hline 1g & 1.1620 & 96.2 & 66 & 0.7942 & 0.9683 \\
\hline 1h & 1.072 & 97 & 65.5 & 0.7490 & 0.9730 \\
\hline 1i & 0.9849 & 97 & 70 & 0.9606 & 0.9356 \\
\hline 1j & 1.116 & 96.5 & 71 & 0.68413 & 0.9564 \\
\hline Average & 1.0978 & & & 0.68413 & 0.96559 \\
\hline
\end{tabular}

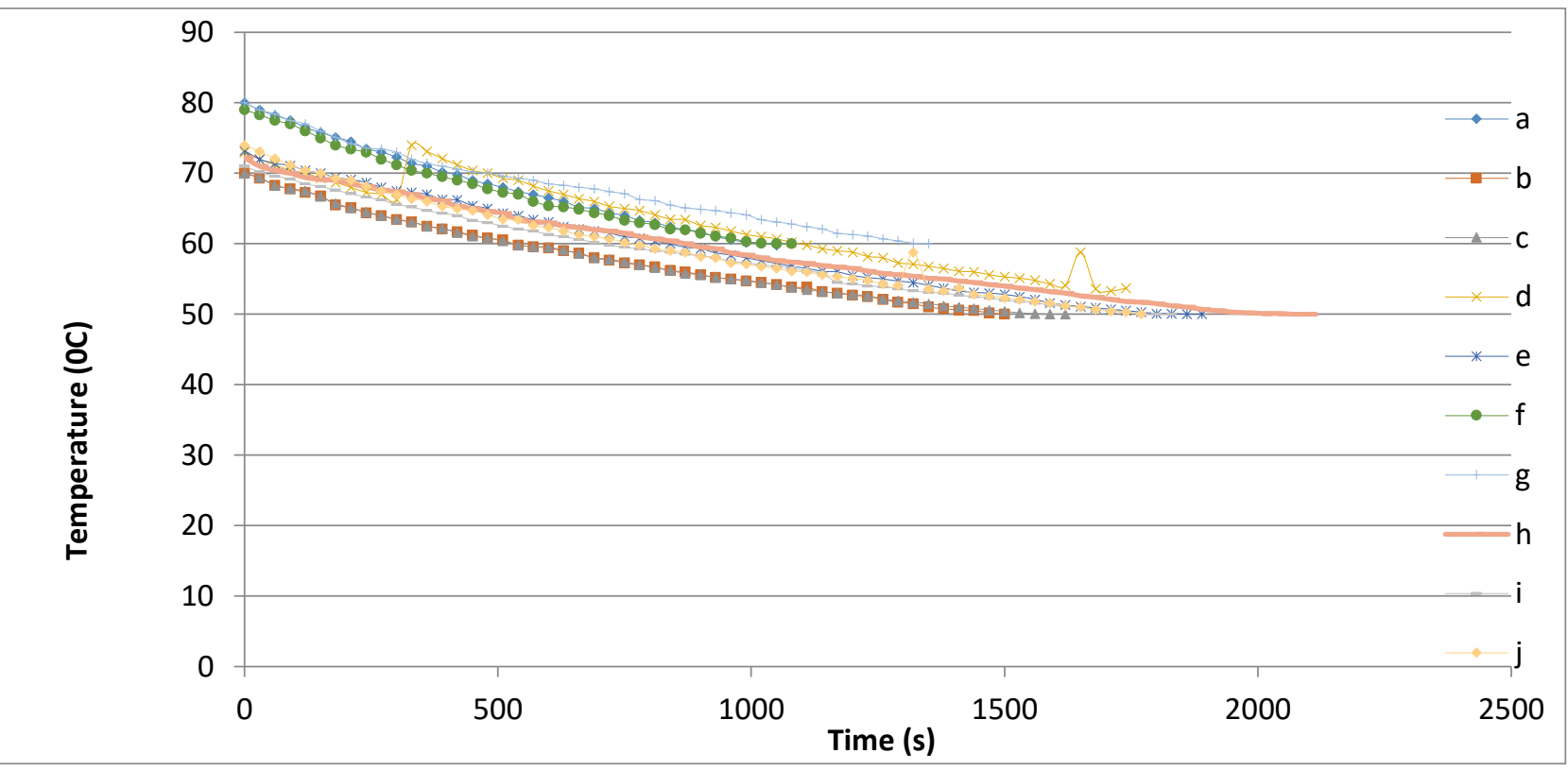

Figure 2: The cooling curve for sample 1 (80:20)

Table 2: Sample $2_{\mathrm{a}-\mathrm{j}}(85: 15)$, measured value

\begin{tabular}{|c|c|c|c|c|c|}
\hline $\begin{array}{c}\text { Sample } \\
\text { Number }\end{array}$ & $\begin{array}{c}\text { Root mean } \\
\text { Square Error } \\
\text { (RMSE) }\end{array}$ & \multicolumn{2}{|c|}{$\begin{array}{c}\text { Discs } \\
\text { Temperature } \\
(\mathbf{O} \mathbf{C})\end{array}$} & $\begin{array}{c}\text { Thermal } \\
\text { Conductivity K } \\
\left.\mathbf{1}_{\mathbf{1}} \mathbf{K}^{-\mathbf{1}}\right)\end{array}$ & $\begin{array}{c}\text { Correlation } \\
\text { Coefficient } \mathbf{R}^{\mathbf{2}}\end{array}$ \\
\cline { 3 - 4 } & & $\mathbf{T}_{\mathbf{2}}$ & $\mathbf{T}_{\mathbf{1}}$ & & \\
\hline 2a & 1.295 & 97.4 & 60 & 0.7821 & 0.9685 \\
\hline 2b & 1.167 & 97 & 63 & 0.7169 & 0.1748 \\
\hline 2c & 0.4549 & 97 & 47 & 0.1911 & 0.9920 \\
\hline 2d & 1.104 & 97 & 70 & 1.3144 & 0.9501 \\
\hline 2e & 0.3894 & 97.2 & 71 & 1.005 & 0.9962 \\
\hline
\end{tabular}


DOI: 10.5281/zenodo.2635654

\begin{tabular}{|c|c|c|c|c|c|}
\hline $2 \mathrm{f}$ & 0.5465 & 97 & 69.5 & 1.3053 & 0.9930 \\
\hline $2 \mathrm{~g}$ & 0.5254 & 96 & 67.3 & 1.0871 & 0.9950 \\
\hline $2 \mathrm{~h}$ & 0.4602 & 96 & 65 & 0.8366 & 0.9946 \\
\hline $2 \mathrm{i}$ & 1.195 & 97 & 68.2 & 0.7448 & 0.9676 \\
\hline $2 \mathrm{j}$ & 0.4354 & 97 & 68 & 1.2103 & 0.9990 \\
\hline Average & 0.7573 & & & & 0.9022 \\
\hline
\end{tabular}

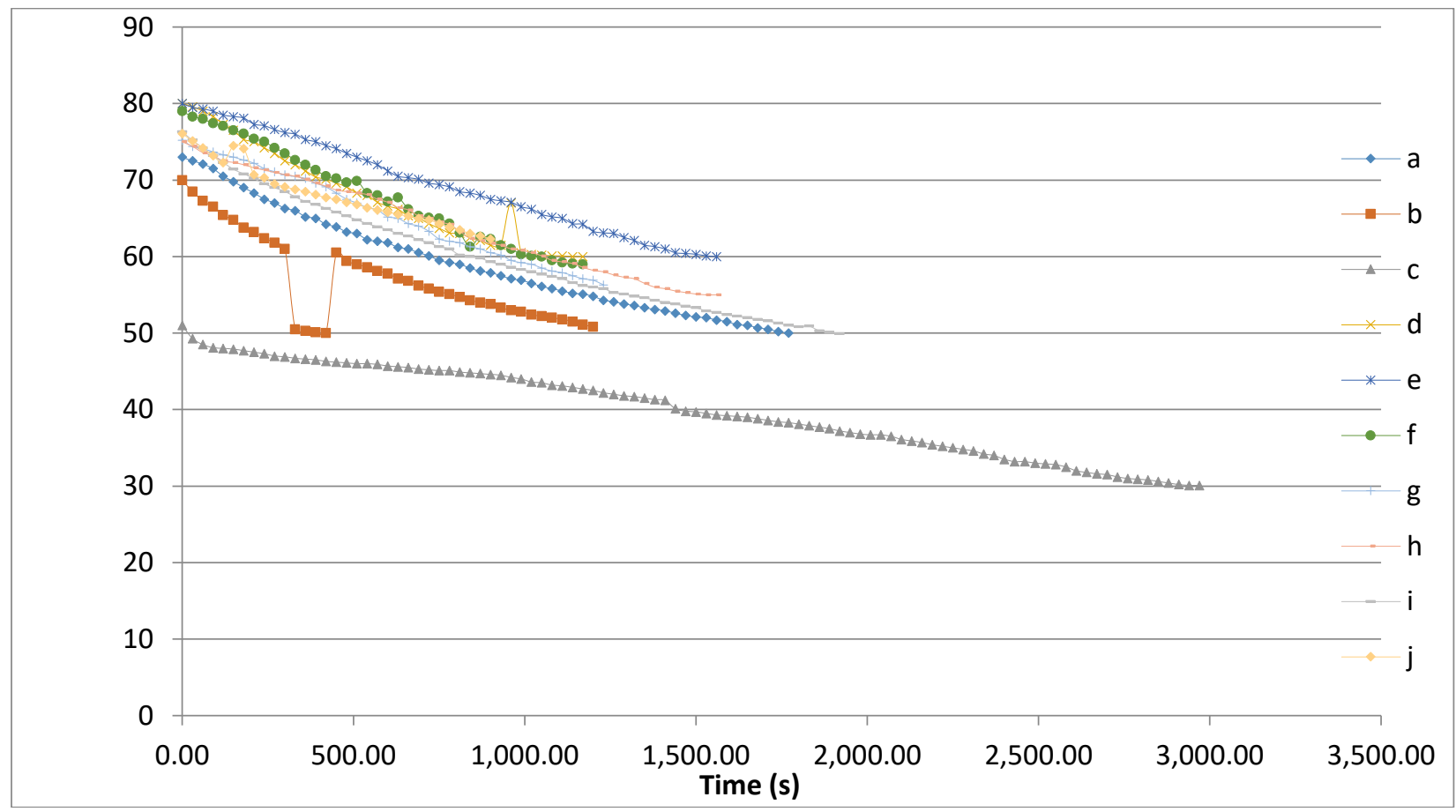

Figure 3: The cooling curve for sample 2 (85:15)

Table 3: Sample $3 \mathrm{a}-\mathrm{j}(90: 10)$, measured values

\begin{tabular}{|c|c|c|c|c|c|}
\hline \multirow{2}{*}{$\begin{array}{c}\text { Sample } \\
\text { Number }\end{array}$} & $\begin{array}{c}\text { Root mean } \\
\text { Square Error } \\
\text { (RMSE) }\end{array}$ & \multicolumn{2}{|c|}{$\begin{array}{c}\text { Disc } \\
\text { Temperature } \\
(\mathbf{O} \mathbf{C})\end{array}$} & \multirow{2}{*}{$\begin{array}{c}\text { Thermal } \\
\text { Conductivity K } \\
\left(\mathbf{W m}^{-\mathbf{1}} \mathbf{K}^{-\mathbf{1}}\right)\end{array}$} & $\begin{array}{c}\text { Correlation } \\
\text { Coefficient } \mathbf{R}^{\mathbf{2}}\end{array}$ \\
\cline { 2 - 4 } & & $\mathbf{T}_{\mathbf{2}}$ & $\mathbf{T}_{\mathbf{1}}$ & & \\
\hline $3 \mathrm{a}$ & 1.438 & 97 & 56.2 & 0.5592 & 0.9617 \\
\hline $3 \mathrm{~b}$ & 0.829 & 96 & 56 & 0.5606 & 0.9862 \\
\hline $3 \mathrm{c}$ & 1.511 & 96.8 & 55.8 & 0.5993 & 0.9508 \\
\hline $3 \mathrm{~d}$ & 0.7862 & 96.9 & 56.1 & 0.5401 & 0.9879 \\
\hline $3 \mathrm{e}$ & 1.3990 & 97 & 56 & 0.6088 & 0.9670 \\
\hline $3 \mathrm{f}$ & 5.769 & 97 & 59.2 & 0.4282 & 0.9921 \\
\hline $3 \mathrm{~g}$ & 0.7601 & 97 & 56 & 0.5660 & 0.9884 \\
\hline $3 \mathrm{~h}$ & 1.0800 & 96.8 & 57 & 0.6908 & 0.9827 \\
\hline $3 \mathrm{i}$ & 1.5450 & 97 & 61 & 0.6161 & 0.9306 \\
\hline $3 \mathrm{j}$ & 1.4201 & 97 & 56.2 & 0.5183 & \\
\hline
\end{tabular}


DOI: 10.5281/zenodo.2635654

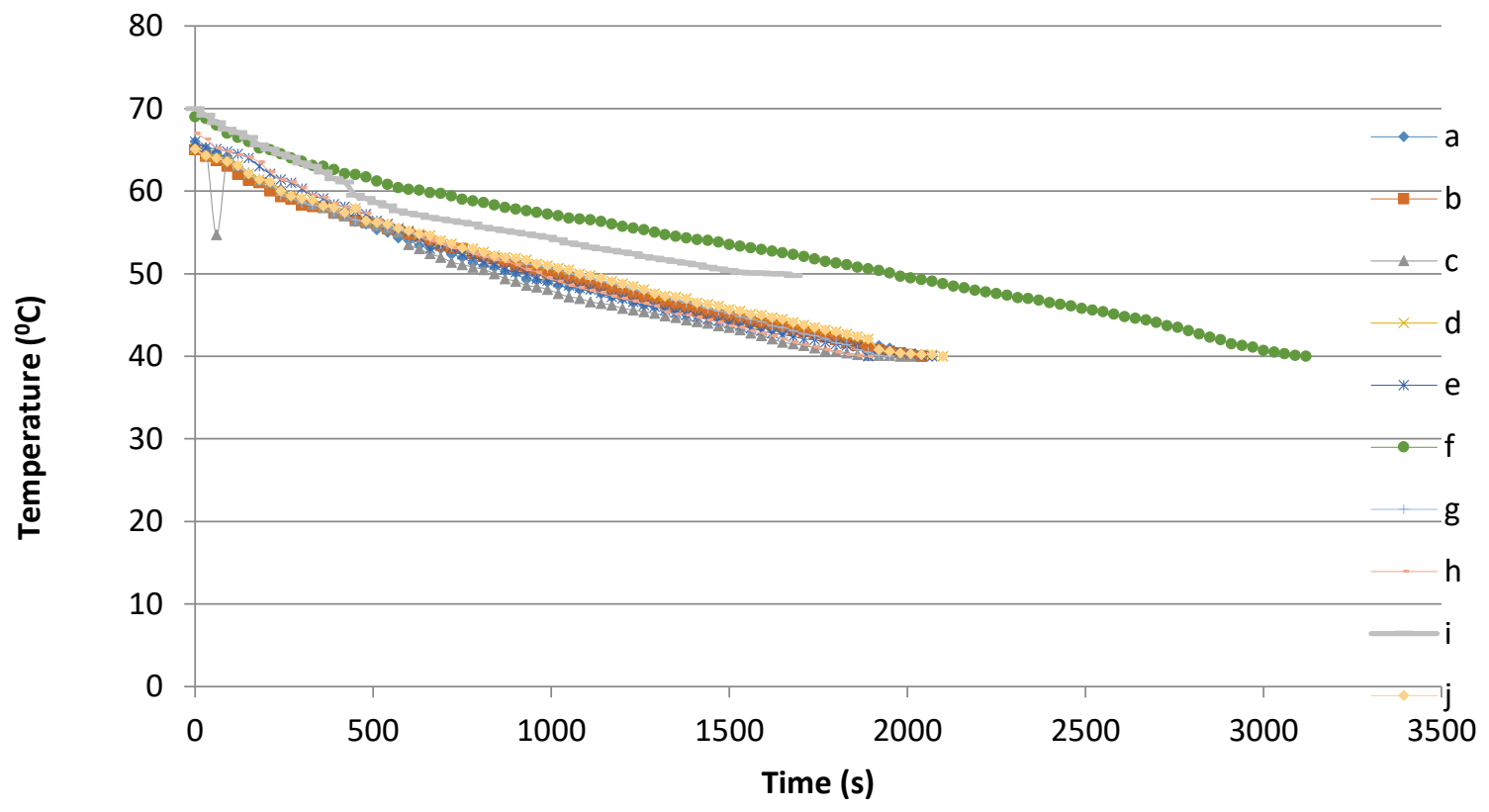

Figure 4: The cooling curve for sample 3 (90:10)

Table 4: The Ratios of Adobe to Quartz and Average Thermal conductivities

\begin{tabular}{|c|c|c|}
\hline S/NO. & Ratios of Adobe to Quartz. & Thermal Conductivity $\left(\mathbf{W m}^{-\mathbf{1}} \mathbf{K}^{-\mathbf{1}}\right) \mathbf{.}$ \\
\hline 1 & $90: 10$ & 0.57 \\
\hline 2 & $80: 20$ & 0.07 \\
\hline 3 & $85: 15$ & 0.92 \\
\hline
\end{tabular}

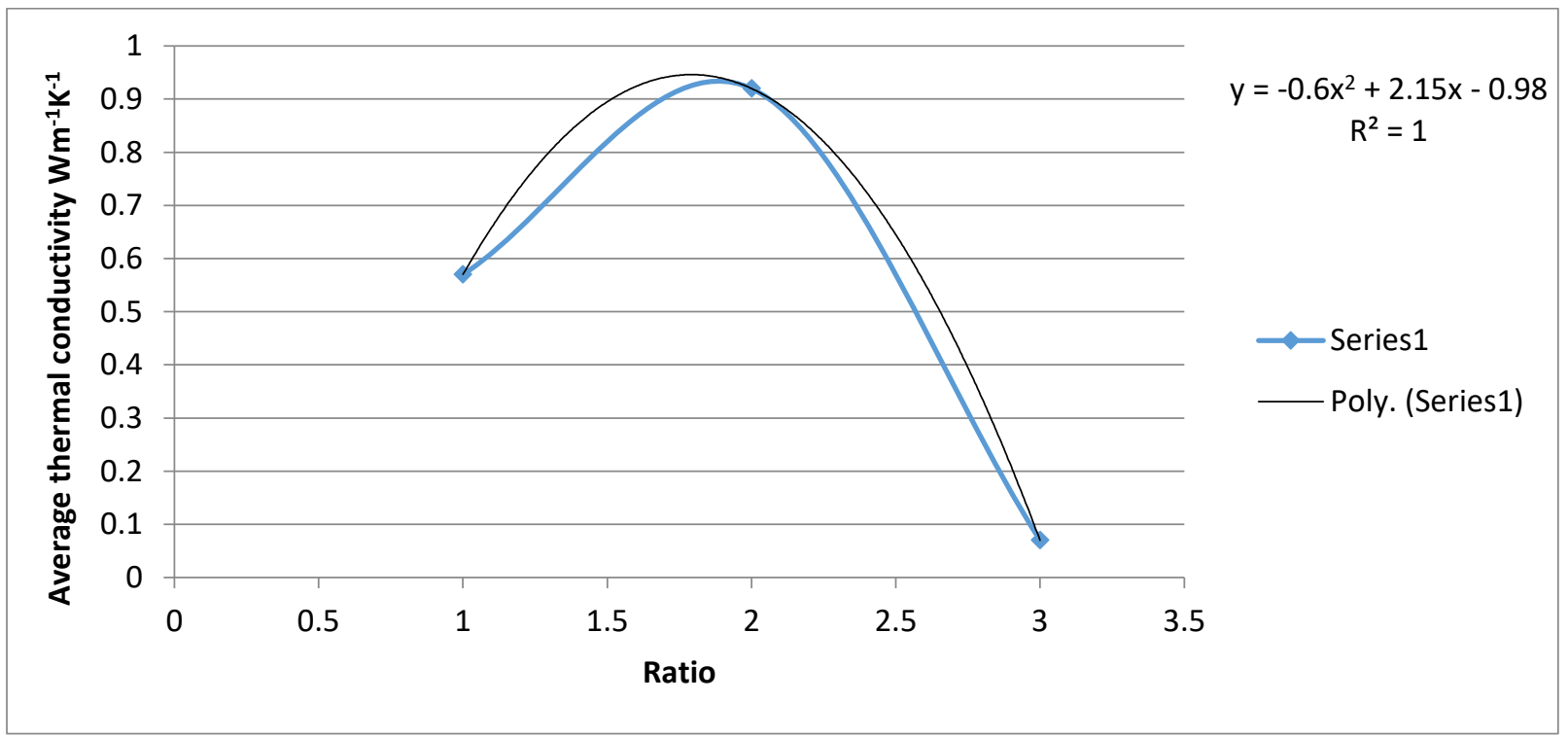

Figure 5: Graph of average thermal conductivities against ratio

This indicates from this experimental result that $10 \%$ portion of sand can be used to decrease the thermal conductivity of the adobe. Decreasing the thermal conductivity of adobe is very important factor to increase its insulation capability and to achieving thermal comfort for its occupants. 
Insulation reduces unwanted heat loss or gain and can decrease the energy demands of heating and cooling systems.

In contrast with $10 \%$ of sand, the other percentages increase the thermal conductivity of the adobe. This might happened due to the mixture, between quartz and adobe.

\section{Conclusion}

There are many examples across the world where adobes mixed with quartz are effectively used. They can be used to improve the quality of the soil; e.g. dry strength, wet strength, water erosion, surface protection etc.

Thermal conductivity of adobe brick is important for thermal insulation purposes. Heat will flow faster through materials that have higher thermal conductivity. On the other hand, materials that have lower conductivity will be suitable to be used as a heat insulator. Three different mixtures of adobe/quartz (90:10, 85:15 and 80:20) were examined by their thermal conductivities, using "Lee's Disc method". The experiments indicated that the first two ratios $(80: 20,85: 15)$ increased the thermal conductivity of the adobe bricks, while the third ratio (90:10) decreased the adobe's thermal conductivity that suitable for building constructions.

Based on this, brick of ratio 90:10 of adobe-quartz should be used to design cottage homes to reduce heating inside the room, and also research should be undertaken to design storage facilities using this ratio of adobe and quartz.

\section{References}

[1] Bansal N.K. (1994). A low cost low energy building, low cost housing and infrastructure. Indian National Academy of Engineering. 28997.

[2] Luisa, P.M., and Batty, W. (2006). Thermal behaviour of adobe constructions. Building and environment 41(12). 1892- 1904.

[3] Cofmann C.V, Duffin R.J, Knowles G.P', (1980). Adobe walls optimal phase shift filters, Advance Applied Mathematics, Vol. 1, pp.50-66.

[4] Deshmukh, M. (1991). Effects of passive features on comfort conditions in buildings. Ph.D. Thesis, I.I.T. Delhi.

[5] Fahriye, H.S. (1976). The use of earth covered buildings. Proc. Conf. on Alternative in Energy Conservation: The use of Earth-Covered buildings, Fort Worth, Texas, Moreland F. (Ed.),: US GPO 038-000-00286-4, 21-26.

[6] Givoni, B. and KatzL. (1985). Earth temperatures and underground buildings. Energy and Buildings 8(1): 15-25.

[7] Ghosal, M.K.., NayakS., TiwariG.N. and SahooN. (2008). Modeling and experimental study for winter performance of an earth to air heat exchanger: An alternative energy source for greenhouse. Agricultural Engineering International: the CIGR Ejournal. Manuscript EE 07012, Vol. X.

[8] Jacovides, C.P., MihalakakouG., SantamourisM. and LewisJ.O. (1996). On the ground temperature profile for passive cooling application in buildings. Solar Energy 57 (3): 167-75.

[9] DuffinR.J, Knowles,G. (1981). Temperature control of buildings by adobe wall design, Solar Energy, Vol. 27, No. 3, pp. 241-249.

[10] DuffinR.J, GregK., (1984). Uses of layered walls to reduce building temperature swings, Solar Energy, Vol. 33, pp.543-549. 
[11] Sodha, M.S., MahajanU. and SawhneyR.L. (1994). Thermal performance of parallel earth air pipe system. Int. J. of Energy Research 18:437-47.

[12] Tassinari, P., TorreggianiD., PaolinelliG. and BenniS. (2007). Rural buildings and their integration on landscape management. Agricultural Engineering International: the CIGR Ejournal. Manuscript LW 07020, Vol. IX.

\footnotetext{
*Corresponding author.

E-mail address: snghshvkmr@ yahoo.co.in
} 